\title{
Perceived Firm Attributes, Social Identification, and Intrinsic Motivation to Voice in Brand Virtual Communities: Differentiating Brand-General and Innovation-Specific Perceptions
}

\author{
Yongqiang Sun \\ Wuhan University \\ sunyq@,whu.edu.cn
}

\author{
Cailian Zhao \\ Wuhan University \\ cailianzhao@whu.edu.cn
}

\author{
Xiao-Liang Shen \\ Wuhan University \\ xlshen@whu.edu.cn
}

\author{
Nan Wang \\ Wuhan University \\ nanwang@,whu.edu.cn
}

\begin{abstract}
The question about why some brand virtual communities (BVCs) successfully motivate customers to engage in value creation (e.g., voice) while others do not is still an important but understudied research issue. To fill this research gap, we propose a research model to shed light on the antecedents of intrinsic motivation to voice by focusing on the role of perceived firm attributes. Specifically, we argue that firm attributes can be classified into brandgeneral versus innovation-specific attributes which affect intrinsic motivation through two types of social identification namely brand identification and community identification respectively. The links between these two types of perceptions are examined too. A field study of 291 BVC users was conducted to test the research model. The results show that customer orientation and perceived openness positively affect customers' brand identification and community identification respectively, and customer orientation has a positive effect on perceived openness. Furthermore, the impact of brand identification on intrinsic motivation is found to be fully mediated by community identification.
\end{abstract}

\section{Introduction}

Brand virtual communities (BVCs) have become not only an important platform for firms to facilitate the interaction with and among customers and brands $[1,2]$, but also become a critical enabler of value cocreation [3]. Value co-creation refers to an interactive process through which at least two actors integrate resources into collaboration and co-create value for all actors [4]. Specifically, in firm-hosted brand communities, firm and consumers are two critical actors of value co-creation [5]. Through integrating consumers into BVCs and encouraging them to engage in new product development (NPD) process, not only customers' needs and wants are better satisfied but also great benefits are achieved for firms [6-8]. By December 2018, the number of HUAWEI community users (https://club.huawei.com/forum152-1.html) has exceeded 100 million. Many users express their voices in HUAWEI BVC, such as feedback about voice assistant and a new design for full screen.

Given that a brand community is a key instrument for connecting customers with a focal brand [9, 10], many researchers have recognized BVCs' value. A lot of previous studies have investigated customers' behaviors in BVCs [11]. However, little has focused on consumers' voice behavior, which refers to the voluntary and autonomous expression of their needs and ideas to promote the brand or product $[12,13]$. As a key process of value co-creation, voice behavior offers necessary innovative sources for a firm to identify for NPD. As no external reward and control is available in BVCs, voice behavior is voluntary and majorly driven by intrinsic motivation [14, 15]. Specifically, intrinsic motivation refers to engaging in an activity for its inherent enjoyment or satisfaction rather than some separable outcomes [15] Several recent studies also suggest that intrinsic motivation is a more important predictor of consumers' engagement in virtual communities [4, 16].

Although prior studies have identified a variety of antecedents of intrinsic motivation including brand attractiveness, brand value, community feedback and information sharing [17-20], they pay less attention to the role of firm attributes in triggering intrinsic motivation. However, regarding the firm interference in firm-hosted BVC activities [21], firm attributes, especially users' perceived firm attributes [6, 22], should play an important role in shaping intrinsic motivation to voice. To fill this research gap, this study attempts to unravel the underlying mechanism about the relationship between firm attributes and intrinsic motivation to voice. The research question can be interpreted as: will firm attributes perceived 
by community members affect their intrinsic motivation to voice in firm-hosted BVC?

Second, existing literature on BVC takes firm attributes as a general concept without distinguishing different types of firm attributes [19, 20]. Based on Spaeth, et al. [6], the proposed framework focuses on certain community-related attributes such as community-based credibility and openness but neglects the brand-related firm attributes. To fill this gap, this study tries to expand the scope of firm attributes by differentiating them into two categories namely brand-general attributes and innovationspecific attributes and explore their differential mechanisms. Therefore, another research question of this study is: how brand-general and innovationspecific firm attributes influence community members' intrinsic motivation to voice?

Finally, consistent with Spaeth, et al. [6], the present research argues that two types of firm attributes may affect voice motivation through different social identification or construction processes. In parallel with the typology of firm attributes according to the brand-general versus innovation-specific dichotomy, social identification can be classified into brand- and community-related identification too. Organizational behavioral literature suggests that different levels (e.g., group vs. organization) of identification are compatible and can be salient at the same time [23]. Given that a brand community is a subordinate group of a brand, we can infer that brand identification and community identification could coexist too. While many prior studies have solely investigated a specific identification (i.e., either brand or community identification) or taken social identification as a general concept $[18,24,25]$, little has simultaneously investigated whether different levels of social identification exert their distinct influences on intrinsic motivation. Thus, the third research question is: how brand identification and community identification play their roles between firm attributes and intrinsic motivation?

To answer these three research questions, we propose a research model to shed light on the impacts of two types of firm attributes (e.g., customer orientation and perceived openness) on intrinsic motivation to voice through two social identification processes (e.g., brand identification and community identification).

\section{Theoretical background}

\subsection{Brand virtual community}

BVC is a virtual environment where geographically dispersed members with shared value, interest and norm can establish relationships with the focal brand or other community members $[2,9]$. Both customers and companies will benefit from potential co-created values and long-lasting relationships in BVC [26]. A lot of prior studies have investigated customer behavior in BVC. Despite lurkers' browsing behavior [1], prior studies mainly focused on customers' observable participating behavior, such as purchase intention [27], knowledge contribution [28] and word of mouth [20]. However, little research has investigated customers' voice behavior. Voice behavior refers to the voluntary and autonomous expression of their needs, ideas and suggestions to promote the brand or product [12, 13]. Regarding voice behavior as an important approach for value co-creation, this study will focus on the antecedents that lead to customers' intrinsic motivation to engage in voice behavior.

Moreover, BVC could be categorized into firmhosted BVC and customer-hosted BVC [29]. In the present research, we focus on firm-hosted BVCs which generally establish a close and long-term relationship with consumers and focus on a single brand [16, 29]. Nevertheless, some researchers argued that a lack of identification with the firm or a misguided perception about corporate community management (e.g., the feeling of limited freedom of expression) will lead to consumers' rejection of BVC [29]. According to cognitive evaluation theory (CET), social perceptions may facilitate or undermine intrinsic motivation [15]. With respect to firm conducts, several studies suggest that consumers' intrinsic motivation can be influenced by the perceptions related to firm attributes. For example, Franke, et al. [22] suggested that firm perceptions including distributive fairness and procedural fairness affect individual motivation to participate in firm innovation. However, how consumers' intrinsic motivations can be affected by firm attributes has rarely been studied in BVCs, although consumer empowerment strategies and user-driven philosophy have been widely applied in practice $[30,31]$. Further, besides the community-based attributes studied by prior studies [6], we also identify another type of firm attributes namely brand-based attribute in this study and try to examine their different impacts.

Given that BVC is a kind of social construction [9], we propose that social identification theory provides us a nuanced perspective to deeply understand the relationships between firm attributes and intrinsic motivation to voice. 


\subsection{Social identification}

Social identification captures the role of social identity through the social categorization process [32]. Individuals who hold common social identification belong to the same social category or group [33]. Specifically, self-categorization and social comparison are two main processes involved in the formation of social identification [34]. Through selfcategorization, individuals recognize that they share same attributes with in-group members and construe themselves as a group member. It is a process of depersonalization to conform to a group's prototype [35]. The more people perceive mental overlaps between self and in-group prototype, the higher their social identification levels [36]. Social comparison indicates that people distinguish themselves as ingroup members from other out-group members, emphasizing and maximizing intergroup differences and in-group similarities.

Further, the formation of social identification depends on contexts [37]. Muniz and O'Guinn [9] identified two relationships in a brand community according to the customer-customer-brand triad. McAlexander, et al. [10] expanded the categories of the relationships in the brand community by including consumers' relationships with the brand, the product, the company and other consumers. An empirical study showed that the customer-product relationship and the customer-brand relationship cannot be distinguished and suggested to eliminate the customer-product relationship from the overall framework [38]. As consumers regard themselves as group members of a specific brand rather than a company, and BVC is more closely related to a specific brand [39], we take brand identification as an important social identification besides community identification which has been widely discussed in prior studies.

Brand identification and community identification are regarded to be coexisting in this study. According to organizational behavior literature, there may be different levels of social identification and these social identifications are compatible in an organization and can be salient at the same time [23]. A dual identity model affirms that both higher and lower order identities, especially for nested identities can coexist [40]. In BVCs, Hsu, et al. [41] pointed out that brand communities can be regarded as brand subgroups. Thus, brand identification is at a superordinate level and community identification is at a lower order level, corresponding to the brandgeneral perception and the innovation-specific perception respectively. Thus, we consider brand identification and community identification as two distinct but coexisting constructs which may further affect consumers' intrinsic motivations to voice.

Although prior studies have examined various consequences of social identification such as word of mouth, brand loyalty, and resilience to negative information $[17,18]$, little research has examined its role in shaping intrinsic motivation to voice in $\mathrm{BVC}$, especially the differential effects of brand identification and community identification. Therefore, this study tries to investigate the role of social identification in the relationship between firm attributes and intrinsic motivation.

Based on CET, the intrinsic motivation would be enhanced when the basic psychological needs for competence, autonomy, and relatedness are fulfilled [15]. Accordingly, the impacts of social identification can be explained the three mechanisms as follows. First, psychological attachment, affective commitment and belongingness stemming from social identification can increase users' motivations to engage in group activities [1,42], which has been supported in BVC $[14,20]$. Second, since social identification is formulated through a comparison between in-group and out-group perceptions, the ingroup membership can promote actions that support the group [43, 44]. Third, social identification could reduce the feeling of self-uncertainty towards an individual's social identity through the selfcategorization process [35], and this sense of security or safety is important for the intrinsic motivation to voice [15].

\section{Research model}

The research model is developed as depicted in Figure 1, and hypotheses will be developed in the following sections.

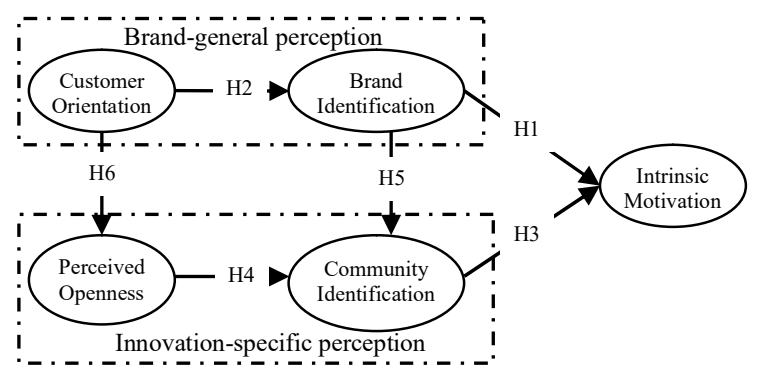

Figure 1. Research model 


\subsection{Brand-general perception and intrinsic motivation}

Brand identification refers to the perception of oneness with a brand, taking the brand's success and failure as one's own [32]. For example, the more prestigious and distinctive the brand is, the higher level of brand identification is, which leads to the enhancement of group self-esteem as a membership [45]. Fulfillment of members' needs for group selfesteem will lead to a higher affective commitment to the brand [1]. Empirical studies have also validated the positive influence of brand identification on brand commitment [17].

Social identification could also reduce the feeling of self-uncertainty towards an individual's social identity through the process of self-categorization [35]. It satisfies individuals' needs for security and relatedness, which is important for the intrinsic motivation to voice [15]. Thus, with greater brand identification, individuals are more intrinsically motivated to support the brand $[1,18]$. Therefore, we hypothesize that:

H1: Brand identification is positively associated with intrinsic motivation.

In marketing research, customer orientation has been broadly accepted as a common belief that customers' interests should be placed in a primary position [46, 47]. Customer orientation is viewed as either an organizational culture or strategic orientation for a firm [48]. The degree of customer orientation depends on consumers' perceptions as well. Thus, customer orientation refers to customers' perceptions with regard to how a company behaves towards customers' needs and ideas [31].

Empirical studies found that customer orientation has a positive effect on brand loyalty and brand association [47]. Such a stronger relationship between consumers and brand encourages brand identification [38]. Second, nowadays groups are generally complex, diverse or with fuzzy attributes [36], the same as BVCs. Perceptions related to a firm's customer orientation help validate the perception of the prototype of a brand, reducing the uncertainty and increasing brand identification. Finally, when the firm is perceived as customer orientated, customers' self-worth for being a member of a brand is enhanced through in-group versus outgroup comparison. Therefore,

H2: Customer orientation is positively associated with brand identification.

\subsection{Innovation-specific perception and intrinsic motivation}

In addition to brand identification, community identification also facilitates intrinsic motivation of voice behavior. Customers construe themselves to be a member of BVC, and they embrace shared identities, shared values, norms and objectives [49]. Some empirical studies have found that community identification is positively associated with satisfaction and commitment to the community [20, 44], which drives community members' engagement in contributing $[14,50]$. Furthermore, community identification could significantly reduce members' perceptions of normative pressure [49], and strengthen the sense of autonomy. Lastly, like brand identification, the sense of security and relatedness can be developed through community identification. Thus, we hypothesize that:

H3: Community identification is positively associated with intrinsic motivation.

Openness refers to the degree to which the firm incorporates customers' ideas generated from the brand community sufficiently [6]. When consumers realize that their ideas are listened and assimilated by the firm, the sense of self-efficacy as well as the value of being a member of the brand community will increase. Thus, we hypothesize that:

H4: Perceived openness is positively associated with community identification.

\subsection{The relationship between brand-general perception and innovation-specific perception}

Previous research has discussed the relationship between brand identification and community identification. Some proposed that community identification positively influence brand identification [51, 52], while the others suggested that brand identification leads to community identification [41, 49]. Form these studies, we can infer that an interplay relationship may exist with some boundary conditions.

In BVC, a brand is the symbolism of a community, the premise and foundation for the establishment of brand virtual community. Accordingly, a brand community is regarded as a subgroup of a brand. Brand identification is a superordinate identity, and community identification is a lower order identity. According to organizational identification literature, a superordinate identity (i.e., brand identification) can help to shape low-order identity (i.e., community identification) [40]. 
Specifically, individuals with higher-order identification (i.e., brand identification) will possess more similar traits and images, and these traits and images will be helpful for the formation of shared values, norms, and interests in the brand community. Additionally, a harmonious relationship with a brand will prompt customers to interact with other group members with shared brand passion [49]. Therefore,

H5: Brand identification is positively associated with community identification.

A customer-oriented firm provides a free, friendly environment for customers to discuss their needs, product suggestions, feedbacks, ideas with a brand and other community members. When a customeroriented firm empowers brand community members to voice and responds to their requests timely, customers will consider the firm to be more open. Conversely, companies which exclusively develop and decide the new product will be perceived as centralized [31], thus the perception of firm openness will be low. Therefore,

H6: Customer orientation is positively associated with perceived openness.

\section{Methodology}

\subsection{Research settings and participants}

Data were collected through a field study in mobile brand virtual community in China. In recent years, mobile phones are widely used everywhere and mobile BVCs are representative to be chosen for investigating this phenomenon. The URLs of the questionnaire was distributed to different brand mobile users. The respondents were judged to be eligible only when they had experience in giving suggestions or ideas in corresponding BVC. Finally, we received 291 valid survey responses. In our sample, male $(56.4 \%)$ and female $(42.6 \%)$ were relatively balanced. Most respondents were between 22 and 35 years $(72.0 \%)$ of age and had a bachelor degree (77.0\%). A majority of respondents had usage experience of a brand virtual community for a year or more $(77.3 \%)$.

\subsection{Measures}

Almost all measurement items were adapted from prior studies with modifications to fit with the specific research context, as shown in Table 1. The questionnaire translation followed a committee approach. All measures used the seven-point Likert scale, from $1=$ strongly disagree to $7=$ strongly agree.

Table 1. Measurements

\begin{tabular}{ll}
\hline Constructs & Items \\
\hline $\begin{array}{l}\text { Customer } \\
\text { orientation }\end{array}$ & CO1 This firm has the customers' best interest \\
i31] & CO2 Thind firm tries to figure out what \\
& customers' needs are.
\end{tabular}

CO3 This firm tries to find out what kind of product would be most helpful to a customer. CO4 This firm tries to get customers to discuss their needs with them.

CO5 Customers can count on this firm to take actions to address customers' needs.

CO6 This firm tries to help customers to achieve their goals.

Firm FO1 I understand how this firm makes

Openness decisions regarding the ideas on its brand [6] community.

FO2 Ideas' contributions are taken up by this firm.

FO3 Ideas on the brand community are sufficiently taken into consideration when this firm makes decisions regarding to the according project.

Brand BI1 When someone praises this firm, it feels Identification like a personal compliment.

[32] BI2 I am very interested in what others think about this firm.

BI3 I feel good when I see a positive report in the media about this firm.

Community CI1 I see myself as a part of the brand Identification community.

[49] CI2 I am very attached to the brand community.

CI3 Other community's members on the brand community and I share the same objectives.

CI4 The friendships I have with other community's members on the brand community mean a lot to me.

CI5 If community's members on the brand community planned something, I'd think of it as something "we" would do rather than something "they" would do.

\begin{tabular}{ll}
\hline Intrinsic & IM1 Contributing ideas on the brand \\
Motivation & community is very interesting. \\
& IM2 The process of contributing ideas on the \\
brand community is very pleasant. & IM3 Participation in idea contribution on the \\
& brand community let me feel a sense of \\
& personal achievement. \\
& IM4 The brand community gives me a chance \\
& to do things I am good at. \\
\hline
\end{tabular}

\section{Data analysis}

The research model was tested using Partial least squares (PLS). PLS has been widely used in 
information system (IS) as the analytic tool due to two main advantages. First, PLS can estimate the loadings (and weights) of indicators on constructs and the causal relationships among constructs in multi-stage models [53]. Second, PLS is more suitable for models with relatively small samples, which is the case in our study [54]. Following a twostage analytical procedure, the measurement model and the structural model were evaluated.

\subsection{Measurement model}

All constructs were treated as reflective constructs. Therefore, the measurement model was assessed by checking the reliability, convergent validity and discriminant validity. Reliability was assessed using composite reliability (CR) and average variance extracted (AVE). As shown in Table 2, the values of $\mathrm{CR}$ were greater than the threshold value 0.7 and the values of AVE were greater than the threshold value 0.5 for all the constructs, exhibiting good construct reliability [55].

Convergent validity was examined by checking whether items loadings within the same construct were adequately high and discriminant validity was assessed by examining if the loadings on the intended constructs were higher than those on other constructs. As shown in Table 3, all item loadings were higher than 0.7 , suggesting good convergent validity [56]. All item loadings on the expected constructs were higher than the loadings on other constructs, indicating good discriminant validity. In addition, the square root of AVE of each construct was greater than the correlations of the expected construct with all the other constructs, reconfirming the good discriminant validity of the constructs [55].

\subsection{Structural model}

The PLS results for the structural model were shown in Figure 2. It was found that $\mathrm{BI}$ had an insignificant impact on IM $(\beta=0.118, \mathrm{t}=1.884)$, so $\mathrm{H} 1$ was not supported. BI significantly affected CI $(\beta=0.395, t=5.409)$, and CI significantly affected IM $(\beta=0.618, t=12.828)$. The results also showed that $\mathrm{CO}$ had a significant positive effect on BI $(\beta=0.466$, $\mathrm{t}=8.046$ ), and FO had a significant positive effect on CI $(\beta=0.369, \mathrm{t}=5.780)$. Thus, H2-H5 were supported. Next, CO significantly influenced FO $(\beta=0.615$, $\mathrm{t}=14.016$ ), supporting H6. All factors of the proposed model explained $47.5 \%$ of the variance for intrinsic motivation.

Regarding the insignificant effect of BI on IM, the mediating effect of $\mathrm{CI}$ was further tested according to the method proposed by Baron and Kenny [57]. As shown in Table 4, when the CI as mediator was added, the influence of BI became insignificant $(\beta=0.120, t=1.941)$. Thus, the impact of $\mathrm{BI}$ on IM is fully mediated by CI.

Table 2. Reliability and correlations

\begin{tabular}{llllllll}
\hline & AVE & CR & BI & CI & CO & FO & IM \\
\hline BI & .614 & .827 & .783 & & & & \\
CI & .565 & .866 & .544 & .752 & & & \\
CO & .542 & .876 & .466 & .630 & .736 & & \\
FO & .598 & .817 & .404 & .529 & .615 & .774 & \\
IM & .590 & .852 & .454 & .682 & .617 & .479 & .768 \\
\hline
\end{tabular}

Notes: The boldfaced and inclined numbers in the diagonal row are square roots of the AVE. BI $=$ Brand identification, $\mathrm{CI}=$ Community identification, $\mathrm{CO}=$ Customer orientation, $\mathrm{FO}=$ Perceived openness, $\mathrm{IM}=$ Intrinsic motivation.

Table 3. Cross-loadings

\begin{tabular}{llllll}
\hline & BI & CI & CO & FO & IM \\
\hline BI1 & $\mathbf{0 . 7 7 9}$ & 0.419 & 0.366 & 0.349 & 0.365 \\
BI2 & $\mathbf{0 . 7 6 9}$ & 0.382 & 0.407 & 0.315 & 0.306 \\
BI3 & $\mathbf{0 . 8 0 2}$ & 0.474 & 0.326 & 0.286 & 0.392 \\
CI1 & 0.426 & $\mathbf{0 . 7 8 3}$ & 0.520 & 0.454 & 0.573 \\
CI2 & 0.320 & $\mathbf{0 . 7 1 3}$ & 0.476 & 0.390 & 0.460 \\
CI3 & 0.355 & $\mathbf{0 . 7 3 1}$ & 0.439 & 0.366 & 0.462 \\
CI4 & 0.419 & $\mathbf{0 . 7 7 0}$ & 0.439 & 0.366 & 0.498 \\
CI5 & 0.502 & $\mathbf{0 . 7 5 9}$ & 0.486 & 0.403 & 0.552 \\
CO1 & 0.393 & 0.431 & $\mathbf{0 . 7 1 1}$ & 0.345 & 0.431 \\
CO2 & 0.330 & 0.383 & $\mathbf{0 . 7 1 5}$ & 0.413 & 0.396 \\
CO3 & 0.357 & 0.466 & $\mathbf{0 . 7 0 8}$ & 0.424 & 0.421 \\
CO4 & 0.252 & 0.488 & $\mathbf{0 . 7 3 5}$ & 0.457 & 0.488 \\
CO5 & 0.303 & 0.492 & $\mathbf{0 . 7 6 8}$ & 0.572 & 0.478 \\
CO6 & 0.419 & 0.512 & $\mathbf{0 . 7 7 6}$ & 0.478 & 0.504 \\
FO1 & 0.305 & 0.327 & 0.442 & $\mathbf{0 . 7 5 5}$ & 0.289 \\
FO2 & 0.327 & 0.465 & 0.505 & $\mathbf{0 . 8 1 6}$ & 0.405 \\
FO3 & 0.304 & 0.421 & 0.476 & $\mathbf{0 . 7 4 7}$ & 0.404 \\
IM1 & 0.328 & 0.497 & 0.449 & 0.320 & $\mathbf{0 . 7 4 3}$ \\
IM2 & 0.329 & 0.539 & 0.505 & 0.420 & $\mathbf{0 . 8 0 0}$ \\
IM3 & 0.364 & 0.509 & 0.432 & 0.344 & $\mathbf{0 . 7 6 1}$ \\
IM4 & 0.372 & 0.546 & 0.505 & 0.382 & $\mathbf{0 . 7 6 8}$ \\
\hline
\end{tabular}

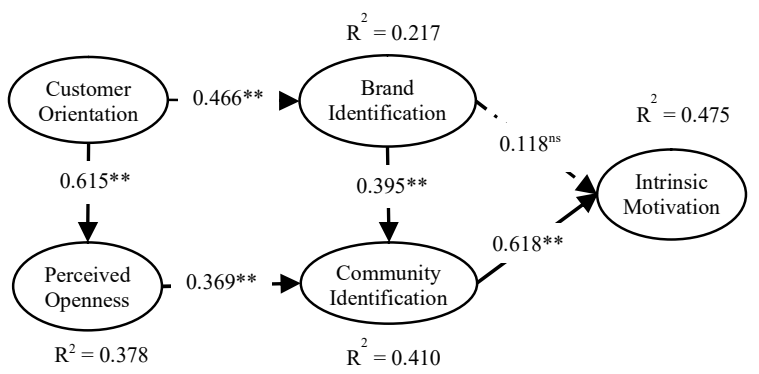

Figure 2. PLS results

Notes: ${ }^{\text {ns }} \mathrm{p}>0.05, * \mathrm{p}<0.05,{ }^{* *} \mathrm{p}<0.01$ 
Table 4. Test of mediation effects

\begin{tabular}{|c|c|c|c|c|c|c|c|}
\hline \multirow[t]{2}{*}{ IV } & \multirow[t]{2}{*}{$\mathrm{M}$} & \multirow[t]{2}{*}{ DV } & \multirow{2}{*}{$\begin{array}{l}\mathrm{IV} \rightarrow \\
\mathrm{DV}\end{array}$} & \multirow{2}{*}{$\begin{array}{c}\mathrm{IV} \rightarrow \\
\mathrm{M}\end{array}$} & \multicolumn{2}{|c|}{$\mathrm{IV}+\mathrm{M} \rightarrow \mathrm{DV}$} & \multirow[t]{2}{*}{ result } \\
\hline & & & & & $\begin{array}{l}\text { IV } \rightarrow \\
\text { DV }\end{array}$ & $\begin{array}{l}\mathrm{M} \rightarrow \\
\mathrm{DV}\end{array}$ & \\
\hline BI & CI & IM & $.458^{* *}$ & $.551^{* *}$ & $.120^{\mathrm{ns}}$ & $.616^{* *}$ & Full \\
\hline
\end{tabular}

\section{Discussion}

\subsection{Key findings}

Several interesting findings can be derived. First, community identification has a direct positive impact on intrinsic motivation, indicating that when customers perceive themselves as belonging to the community, they are more likely to give ideas. Further, brand identification was found to insignificantly affect intrinsic motivation, and a posthoc analysis suggested that this effect was fully mediated by community identification. A plausible explanation for the mediating effect is provided as follows. The identity-matching principle points out that identification with a given level will most strongly affect those potential outcomes at the same level [40]. It is evident that intrinsic motivation to voice in community is an innovation-specific dependent variable. As mentioned above, therefore, the impact of brand-general identification (i.e., brand identification) on intrinsic motivation to voice is fully mediated by innovation-specific identification (i.e., community identification).

Second, customer orientation and perceived openness are two types of firm attributes, which respectively and positively affect brand identification and community identification. The results show how firm significantly influences customers' perception and motivation. Finally, customer orientation can strengthen perceived openness, indicating that when the firm pays more attention to customers' interest and needs, it will be more likely for this firm to be perceived as openness.

\subsection{Theoretical implications}

This study contributes to BVC literature in three ways. First, this study offers a theoretical understanding of customers' voice behaviors in BVC. Although voice behavior is a core process of value co-creation, it is different from co-creation. Consumers' voice behaviors occur when individuals possess the need for the expression about a brand or a product even there is no interaction with the brand and other consumers, while co-creation occurs only in a joint environment where at least two parities interact [4]. As a critical source of innovation, voice behavior can be investigated in future research.

Second, our study contributes to the BVC-related literature by differentiating brand-general and innovation-specific perceptions. Previous studies rarely studied the role of firm attributes or just examined the firm attributes which are perceived as community-based attributes [6]. Given the positive effect of brand attractiveness on intrinsic motivation [18], brand-based firm attributes are worth to study. To our knowledge, this is the first study which simultaneously examines the impacts of brandgeneral attributes and innovation-specific attributes on intrinsic motivation to voice. The proposed hierarchical framework leads to an advanced theoretical understanding about the underlying mechanism of general versus specific perceptions, which could serve as a base for future studies.

Third, our study distinguishes two levels of social identification from a dual identification perspective. Little study has simultaneously investigated the effects of these two levels of identification on intrinsic motivation [6, 58]. In addition, previous research generally suggests that multiple identifications are positively correlated [40]. Further, our study identifies the full mediating role of community identification. Specifically, it suggests that superordinate identification is positively predict subgroup identification, and only through subgroup identification could superordinate identification exert its impact on intrinsic motivation. Thus, our research findings enrich the theoretical understanding about the interplay between multiple social identifications in the context of BVC.

\subsection{Practical implications}

The practical implications are also meaningful for managers. First, firm managers should realize that firm attributes greatly influence participants' intrinsic motivation. Specifically, customer orientation and firm openness are two main firm attributes which should be absorbed by firm managers. For example, a firm should establish an effective interactive response design embedded in BVC to let customer understand a firm's effort in being customer orientation.

Second, enhancing community identification should be the primary choice for mangers because only through community identification could customers perceive a secure base to voice. While the role of brand identification is equally or more important because it's about the quality of the voice behavior and the word of mouth to be positive or negative. It is recommended that managers should 
leverage community identification and brand identification. For example, managers could set an attractive brand-related topic for customers to discuss and build small groups through personalization.

\subsection{Limitations and future research}

There are several limitations which can be addressed through future research. First, due to the data were collected in China, whether the findings can be generalized to other countries still calls for future research. Second, the research only considered two main attributes perceived by customers. Future studies should take other firm attributes such as knowledge support and firm responsibility into account so as to provide a deeper understanding. Third, since this study was conducted in a specific brand community, scholars can further explore whether the findings still hold across different product types (e.g., high involvement products vs. low involvement products), brand types (e.g., luxury brand vs. general brand), and firm types (single-brand firm vs. multi-brand firm). Finally, this study only considered social identity, while the role of the other important self-concept namely self-identity was not investigated [32]. Self-identity refers to an individual's idiosyncratic characteristics, which distinguish himself or herself from other ingroup members [40], it is supposed to affect intrinsic motivation through triggering the feeling of competence [34]. However, because the key objective of this study was to examine the role of firm attributes which majorly affected intrinsic motivation through social identification processes. Future research can consider both social identity and self-identity and compare their differential impacts on intrinsic motivation.

\section{Acknowledgements}

The work described in this paper was partially supported by the National Natural Science Foundation of China (71974148, 71904149) and the Humanities and Social Sciences Foundation of the Ministry of Education, China (16YJC870011, 17YJC630157).

\section{References}

[1] S. Mousavi, S. Roper, and K. A. Keeling, "Interpreting Social Identity in Online Brand Communities: Considering Posters and Lurkers," Psychology \& Marketing, vol. 34, pp. 376-393, Apr 2017.

[2] R. J. Brodie, A. Ilic, B. Juric, and L. Hollebeek, "Consumer engagement in a virtual brand community: An exploratory analysis," Journal of Business Research, vol. 66, pp. 105-114, Jan 2013.

[3] P. Skalen, S. Pace, and B. Cova, "Firm-brand community value co-creation as alignment of practices," European Journal of Marketing, vol. 49, pp. 596-620, 2015. [4] T. Fernandes and P. Remelhe, "How to engage customers in co-creation: customers' motivations for collaborative innovation," Journal of Strategic Marketing, vol. 24, pp. 311-326, 2016

[5] R. C. Gambetti and G. Graffigna, "Value co-creation between the "inside' and the "outside' of a company: Insights from a brand community failure," Marketing Theory, vol. 15, pp. 155-178, Jun 2015.

[6] S. Spaeth, G. von Krogh, and F. He, "Perceived Firm Attributes and Intrinsic Motivation in Sponsored Open Source Software Projects," Information Systems Research, vol. 26, pp. 224-237, Mar 2015.

[7] Y. Q. Sun, Y. L. Fang, and K. H. Lim, "Understanding sustained participation in transactional virtual communities," Decision Support Systems, vol. 53, pp. 12 22, Apr 2012.

[8] C. Fuchs, E. Prandelli, and M. Schreier, "The Psychological Effects of Empowerment Strategies on Consumers' Product Demand," Journal of Marketing, vol. 74, pp. 65-79, Jan 2010.

[9] A. M. Muniz and T. C. O'Guinn, "Brand community," Journal of Consumer Research, vol. 27, pp. 412-432, Mar 2001.

[10] J. H. McAlexander, J. W. Schouten, and H. F. Koenig, "Building brand community," Journal of Marketing, vol. 66, pp. 38-54, Jan 2002.

[11] M. Hook, S. Baxter, and A. Kulczynski, "Antecedents and consequences of participation in brand communities: a literature review," Journal of Brand Management, vol. 25, pp. 277-292, Jul 2018.

[12] N. Bharadwaj, J. R. Nevin, and J. P. Wallman, "Explicating Hearing the Voice of the Customer as a Manifestation of Customer Focus and Assessing its Consequences," Journal of Product Innovation Management, vol. 29, pp. 1012-1030, Nov 2012.

[13] M. R. Bashshur and B. Oc, "When Voice Matters: A Multilevel Review of the Impact of Voice in Organizations," Journal of Management, vol. 41, pp. 15301554, Jul 2015.

[14] S. Ray, S. S. Kim, and J. G. Morris, "The Central Role of Engagement in Online Communities," Information Systems Research, vol. 25, pp. 528-546, Sep 2014.

[15] R. M. Ryan and E. L. Deci, "Self-determination theory and the facilitation of intrinsic motivation, social development, and well-being," American Psychologist, vol. 55, pp. 68-78, Jan 2000.

[16] K. Teichmann, N. E. Stokburger-Sauer, A. Plank, and A. Strobl, "Motivational Drivers of Content Contribution to Company-Versus Consumer-Hosted Online Communities," Psychology \& Marketing, vol. 32, pp. 341-355, Mar 2015. [17] U. Tuskej, U. Golob, and K. Podnar, "The role of consumer-brand identification in building brand relationships," Journal of Business Research, vol. 66, pp. 53-59, Jan 2013.

[18] A. M. Elbedweihy, C. Jayawardhena, M. H. Elsharnouby, and T. H. Elsharnouby, "Customer 
relationship building: The role of brand attractiveness and consumer-brand identification," Journal of Business Research, vol. 69, pp. 2901-2910, Aug 2016.

[19] J. Liao, M. Huang, and B. Xiao, "Promoting continual member participation in firm-hosted online brand communities: An organizational socialization approach," Journal of Business Research, vol. 71, pp. 92-101, Feb 2017.

[20] M. Demiray and S. Burnaz, "Exploring the impact of brand community identification on Facebook: Firmdirected and self-directed drivers," Journal of Business Research, vol. 96, pp. 115-124, Mar 2019.

[21] S. Norskov, Y. M. Antorini, and M. B. Jensen, "INNOVATIVE BRAND COMMUNITY MEMBERS AND THEIR WILLINGNESS TO SHARE IDEAS WITH COMPANIES," International Journal of Innovation Management, vol. 20, Aug 2016.

[22] N. Franke, P. Keinz, and K. Klausberger, "'Does This Sound Like a Fair Deal?": Antecedents and Consequences of Fairness Expectations in the Individual's Decision to Participate in Firm Innovation," Organization Science, vol. 24, pp. 1495-1516, Sep-Oct 2013.

[23] F. Rink and N. Ellemers, "Diversity as a basis for shared organizational identity: The norm congruity principle," British Journal of Management, vol. 18, pp. S17-S27, Mar 2007.

[24] M. Lopez, M. Sicilia, and A. Alejandro MoyedaCarabaza, "Creating identification with brand communities on Twitter The balance between need for affiliation and need for uniqueness," Internet Research, vol. 27, pp. 21-51, 20172017.

[25] S. H. Wu, S. C. T. Huang, C. Y. D. Tsai, and P. Y. Lin, "Customer citizenship behavior on social networking sites The role of relationship quality, identification, and service attributes," Internet Research, vol. 27, pp. 428-448, 2017.

[26] M. A. Merz, L. Zarantonello, and S. Grappi, "How valuable are your customers in the brand value co-creation process? The development of a Customer Co-Creation Value (CCCV) scale," Journal of Business Research, vol. 82, pp. 79-89, Jan 2018.

[27] J. Wu, L. Huang, J. L. Zhao, and Z. Hua, "The deeper, the better? Effect of online brand community activity on customer purchase frequency," Information \& Management, vol. 52, pp. 813-823, 11/1/November 20152015.

[28] Y. C. Wang and D. R. Fesenmaier, "Towards understanding members' general participation in and active contribution to an online travel community," Tourism Management, vol. 25, pp. 709-722, Dec 2004.

[29] J. Breitsohl, W. H. Kunz, and D. Dowell, "Does the host match the content? A taxonomical update on online consumption communities," Journal of Marketing Management, vol. 31, pp. 1040-1064, 2015.

[30] D. W. Dahl, C. Fuchs, and M. Schreier, "Why and When Consumers Prefer Products of User-Driven Firms: A Social Identification Account," Management Science, vol. 61, pp. 1978-1988, Aug 2015.

[31] C. Fuchs and M. Schreier, "Customer Empowerment in New Product Development," Journal of Product Innovation Management, vol. 28, pp. 17-32, Jan 2011.

[32] F. Mael and B. E. Ashforth, "ALUMNI AND THEIR ALMA-MATER - A PARTIAL TEST OF THE
REFORMULATED MODEL OF ORGANIZATIONAL IDENTIFICATION," Journal of Organizational Behavior, vol. 13, pp. 103-123, Mar 1992.

[33] J. C. Turner and P. J. Oakes, "THE SIGNIFICANCE OF THE SOCIAL IDENTITY CONCEPT FOR SOCIALPSYCHOLOGY WITH REFERENCE TO INDIVIDUALISM, INTERACTIONISM AND SOCIALINFLUENCE," British Journal of Social Psychology, vol. 25, pp. 237-252, Sep 1986.

[34] J. E. Stets and P. J. Burke, "Identity theory and social identity theory," Social Psychology Quarterly, vol. 63, pp. 224-237, Sep 2000

[35] M. A. Hogg and M. J. Rinella, "Social identities and shared realities," Current Opinion in Psychology, vol. 23, pp. 6-10, Oct 2018

[36] R. van Veelen, S. Otten, M. Cadinu, and N. Hansen, "An Integrative Model of Social Identification: SelfStereotyping and Self-Anchoring as Two Cognitive Pathways," Personality and Social Psychology Review, vol. 20, pp. 3-26, Feb 2016.

[37] G. Marzocchi, G. Morandin, and M. Bergami, "Brand communities: loyal to the community or the brand?," European Journal of Marketing, vol. 47, pp. 93-114, 2013 2013.

[38] N. Stokburger-Sauer, "Brand Community: Drivers and Outcomes," Psychology \& Marketing, vol. 27, pp. 347-368, Apr 2010

[39] F. D. a. Freitas and V. M. C. de Almeida, "Theoretical Model of Engagement in the Context of Brand Communities," Brazilian Business Review (Portuguese Edition), vol. 14, pp. 86-107, 2017.

[40] B. E. Ashforth, S. H. Harrison, and K. G. Corley, "Identification in organizations: An examination of four fundamental questions," Journal of Management, vol. 34, pp. 325-374, Jun 2008.

[41] L. C. Hsu, W. H. Chih, and D. K. Liou, "Understanding community citizenship behavior in social networking sites An extension of the social identification theory," Industrial Management \& Data Systems, vol. 115, pp. 1752-1772, 2015.

[42] M. Bergami and R. P. Bagozzi, "Self-categorization, affective commitment and group self-esteem as distinct aspects of social identity in the organization," British Journal of Social Psychology, vol. 39, pp. 555-577, Dec 2000.

[43] R. P. Bagozzi and U. M. Dholakia, "INTENTIONAL SOCIAL ACTION IN VIRTUAL COMMUNITIES," Journal of Interactive Marketing (John Wiley \& Sons), vol. 16, pp. 2-21, Spring2002 2002.

[44] H.-T. Tsai and R. P. Bagozzi, "CONTRIBUTION BEHAVIOR IN VIRTUAL COMMUNITIES: COGNITIVE, EMOTIONAL, AND SOCIAL INFLUENCES," Mis Quarterly, vol. 38, pp. 143-+, Mar 2014.

[45] N. Stokburger-Sauer, S. Ratneshwar, and S. Sen, "Drivers of consumer-brand identification," International Journal of Research in Marketing, vol. 29, pp. 406-418, Dec 2012.

[46] R. Deshpandé, J. U. Farley, and F. E. Webster Jr, "Corporate Culture Customer Orientation, and 
Innovativeness in Japanese Firms: A Quadrad Analysis," Journal of Marketing, vol. 57, pp. 23-37, 1993.

[47] H. Y. Ha and J. John, "Role of customer orientation in an integrative model of brand loyalty in services," Service Industries Journal, vol. 30, pp. 1025-1046, 2010.

[48] S. Auh and B. Mengue, "Performance implications of the direct and moderating effects of centralization and formalization on customer orientation," Industrial Marketing Management, vol. 36, pp. 1022-1034, Nov 2007. [49] R. Algesheimer, U. M. Dholakia, and A. Herrmann, "The social influence of brand community: Evidence from European car clubs," Journal of Marketing, vol. 69, pp. 1934, Jul 2005.

[50] P. J. Bateman, P. H. Gray, and B. S. Butler, "The Impact of Community Commitment on Participation in Online Communities," vol. 22, ed, 2011, pp. 841-854.

[51] Z. Zhou, Q. Zhang, C. Su, and N. Zhou, "How do brand communities generate brand relationships? Intermediate mechanisms," Journal of Business Research, vol. 65, pp. 890-895, 2012.

[52] R. P. Bagozzi and U. M. Dholakia, "Antecedents and purchase consequences of customer participation in small group brand communities," International Journal of Research in Marketing, vol. 23, pp. 45-61, Mar 2006.

[53] C. Fornell and F. L. Bookstein, "Two Structural Equation Models: LISREL and PLS Applied to Consumer Exit-Voice Theory," Journal of Marketing Research (JMR), vol. 19, p. 440, 11// 1982.

[54] F. H. Joe, M. R. Christian, and S. Marko, "PLS-SEM: INDEED A SILVER BULLET," Journal of Marketing Theory and Practice, vol. 19, p. 139, 2011.

[55] C. Fornell and D. F. Larcker, "Evaluating Structural Equation Models with Unobservable Variables and Measurement Error," Journal of Marketing Research (JMR), vol. 18, p. 39, 02// 1981.

[56] D. Gefen and D. Straub, "A PRACTICAL GUIDE TO FACTORIAL VALIDITY USING PLS-GRAPH: TUTORIAL AND ANNOTATED EXAMPLE," Communications of the Association for Information Systems, vol. 16, pp. 91-109, 2005.

[57] R. M. Baron and D. A. Kenny, "THE MODERATOR MEDIATOR VARIABLE DISTINCTION IN SOCIAL PSYCHOLOGICAL-RESEARCH - CONCEPTUAL, STRATEGIC, AND STATISTICAL CONSIDERATIONS," Journal of Personality and Social Psychology, vol. 51, pp. 1173-1182, Dec 1986.

[58] F. J. Martinez-Lopez, R. Anaya-Sanchez, S. Molinillo, R. Aguilar-Illescas, and I. Esteban-Millat, "Consumer engagement in an online brand community," Electronic Commerce Research and Applications, vol. 23, pp. 24-37, May-Jun 2017. 